\title{
23. PHYSICAL PROPERTIES DATA AT HOLE 959D: COMPARISON OF CORE AND LOG MEASUREMENTS AND A PROPOSED REVISION OF LITHOLOGIC UNITS ${ }^{1}$
}

\author{
A.G. Janik, ${ }^{2}$ J.A. Hood, ${ }^{2}$ and M.V. Ask ${ }^{3}$
}

\begin{abstract}
A revised division of lithologic units is proposed for Hole 959D in the interval from 400 to 1000 meters below seafloor from Ocean Drilling Program Leg 159 based on combining the geophysical and sedimentological information. This new division is essential for further geological studies of the Cote d'Ivoire-Ghana Transform Margin area. A comparison is made between shipboard laboratory measurements made on core samples and in situ downhole logging data. Logging data, in conjunction with physical properties data, provide a more detailed record of the variation in the sediment column, which enables a more qualitative assessment of lithotype distribution. Emphasis is placed on distinguishing between the lithologic factors influencing the geophysical signals and artifacts resulting from imperfect data collection. Good overall agreement between core and log data for rotary core barrel cored sediments at Hole 959D is observed, and effects of core expansion caused by the removal of overburden pressure do not appear significant.
\end{abstract}

\section{INTRODUCTION}

During Ocean Drilling Program (ODP) Leg 159, four sites were drilled along the ridge of the Côte d'Ivoire-Ghana Transform Margin (Sites 959-962). The primary goals of the cruise were to understand the geological processes related to the formation of the marginal ridge (Basile et al., 1993; Edwards et al., 1997) and to reconstruct the continental breakup history by an investigation of the characteristics of recovered sediments (Shipboard Scientific Party, 1996b). An extensive set of physical properties data was collected both in situ from downhole logging and in the laboratory, using both the multisensor track (MST) and discrete sample measurements. The data used for analyses include core data from the interval from 417.8 to 1158.9 meters below seafloor (mbsf) cored with a 59\% recovery, and log data that were collected in the interval from $~ 400$ to $1100 \mathrm{mbsf}$ at Hole 959D. These different data types provide both in situ and laboratory measurements, which can then be compared to test their reliability as an aid in further geological analysis. Core data from the discrete measurements are considered more reliable than the MST data in this interval because the core was drilled with the rotary core barrel (RCB), which degrades the quality of the MST data because of core disturbances and variations of core diameter in the liner, whereas the discrete measurements are representative of the core chosen from the least disturbed intervals. One of the objectives of this study is to establish some degree of ground truth for laboratory and in situ measurements by comparing the two types of data collected at Hole 959D and separating the discrepancies between the data sets caused by measurement inaccuracy from those that are related to the lithologic characteristics of the sediments themselves. Another goal is to use the results of the petrophysical data to re-evaluate the lithologic unit boundaries based only on shipboard sedimentological observations.

'Mascle, J., Lohmann, G.P., and Moullade, M. (Eds.), 1998. Proc. ODP, Sci. Results, 159: College Station, TX (Ocean Drilling Program).

${ }^{2}$ Division of Marine Geology and Geophysics, Rosenstiel School of Marine and Atmospheric Science, University of Miami, Miami, FL 33149-1098, U.S.A. ajanik@rsmas.miami.edu

${ }^{3}$ Engineering Geology, Royal Institute of Technology, S-100 44 Stockholm, Sweden.

\section{ANALYTICAL METHODS Density}

Downhole logging, gamma-ray attenuation porosity evaluator (GRAPE) measurements, and discrete index properties measurements provide three methods of determining sediment density. The GRAPE density sampling interval at Hole 959D was $2 \mathrm{~cm}$, the standard mode sampling for logging density measurements was $15 \mathrm{~cm}$, and samples for discrete density measurements were taken at least three times per full core.

The GRAPE sensor utilizes the attenuation of gamma-ray radiation passing through the sediments to estimate density. The GRAPE sensor on the MST provides a high-resolution record of sediment density measured on whole cores. Constant volume of sediments in the liner is assumed. Thus, any disturbances, voids, or slurry will generate an underestimation of density. "Dropouts" also occur at section and core boundaries (Lovell and Morin, 1989). Consequently, utilization of GRAPE density data for geological analysis should proceed only after careful editing of the raw data to remove erroneous data points and correction for effects such as change in coring technique. The best quality GRAPE data are typically obtained from advanced piston coring (APC).

The high-temperature lithodensity tool (HLDT) contains a cesium source of gamma rays (Shipboard Scientific Party, 1996a). When applied to the borehole wall, the source emits medium-energy gamma rays. The gamma rays lose energy because of Compton scattering on the electrons in the formation. The scattered gamma rays reaching the detector are proportional to the electron density of the formation, which then enables the determination of formation bulk density (Schlumberger, 1989). In addition to bulk density, the tool measures the photoelectric absorption and standoff. Therefore, a correction for excessive borehole roughness is also available. This correction is very important because any loss of contact between the sensor and the borehole will cause the density tool to detect a combination of real formation density and the density of the borehole fluid (seawater), leading to an underestimation of formation density. Thus, for data points with high values of bulk density correction (DRHO), the reported density values may be inaccurate. The editing process of the density log was based on the comparison of intervals with anomalously low densities with DRHO corrections, caliper, and core data. Whenever low density values coincided with a high DRHO correction, the density dropouts were deleted. Because these intervals were 
small, the density values were interpolated in the gaps. The edited intervals were at the following depths: 476, 777, 799, 842, 867, 876, 871, and 930 mbsf.

GRAPE and density logging both utilize gamma-ray radiation attenuation to estimate bulk density. In contrast, index property density is determined from gravimetric means, a measurement of mass (measured with a SCITECH balance), and volume (measured using a helium-displacement pycnometer). The bulk of the errors in index properties data are due to the inaccuracy in the estimation of wet volume. The occasional sampling of "constant volume" (Shipboard Scientific Party, 1996a) in soft sediments was not very accurate, as the sampling syringe required some compression of the sediment to fill it. Obtained volume was operator dependent and therefore led to inconsistent results. In addition, the pycnometer is very sensitive to changes in ambient pressure and temperature, so constant recalibration is necessary, which was not always possible because of time constraints. The problems associated with the pycnometer calibrations were reported by O'Brien and Manghnani (1992), who compared shipboard data with shore-based results and found that discrepancies between bulk densities were due to the underestimation of wet volumes by the shipboard helium-displacement pycnometer. To obtain better quality index properties data, measurements of wet volume should be discontinued. Instead, index properties should be calculated from wet weights, dry weights, dry volumes, and the density of the pore water. This protocol is not only more accurate, but also more efficient, allowing more time for pycnometer calibrations which should lead to a more consistent index properties data set.

Downhole density data are very sensitive to hole conditions and GRAPE densities are strongly affected by core disturbances, especially because Hole 959D was RCB cored. Although these measurements provide an almost continuous record of density variation with depth, the index properties are made with more precision and are therefore more reliable. However, samples were taken only from undisturbed intervals, which may have led to some bias, but resulted in measurements that were less sensitive to core disturbances. Therefore, as a means of comparing the log and core data, and in the discussion on the correction for laboratory vs. in situ values, only index properties data are presented as a representation of the shipboard core data.

\section{Velocity}

As standard ODP procedure, compressional- or $P$-wave velocity is determined by three different methods: (1) in situ determined by downhole logging, (2) shipboard using the $P$-wave Logger (PWL) through the core liner on whole-round core sections, and (3) shipboard using the digital sound velocimeter (DSV) on discrete samples from split cores (Shipboard Scientific Party, 1996a).The standard mode sampling for logging velocity measurements was $15 \mathrm{~cm}$. The PWL was switched off at Hole 959D because there was no contact between sediments and the liner. Samples for discrete velocity measurements were taken once per section.

The array-sonic digital tool (Schlumberger, 1989) provides fullwave recording as a standard feature. The tool contains two broadband piezoelectric transmitters spaced $2 \mathrm{ft}$ apart, and two piezoelectric receivers, located $3 \mathrm{ft}$ and $5 \mathrm{ft}$ above the upper transmitter. In addition, the tool has an array of eight piezoelectric receivers, with the closest receiver $8 \mathrm{ft}$ from the upper transmitter. Because of the number of receivers, the full-waveform recording, and the digital transmission, the array-sonic tool provides a large amount of acoustic information from which, for example, Stonley-wave or shear-wave velocities can be obtained. For the construction of synthetic seismograms (Edwards, Chap. 22, this volume) and integration with core measurements, both short-spaced (3-5 ft) and long-spaced (5-7 ft) $P$-wave velocities are used. Sonic $P$-wave velocities at Hole 959D were processed at Lamont-Doherty Earth Observatory's Borehole
Research Group to suppress some of the noise and eliminate cycle skipping. Also, depth shifting was performed using gamma-ray logs. Additional editing was applied to three small intervals (less than 1.5 $\mathrm{m}$ each), where the values of velocity were erroneously small. After visual examination of superimposed plots of the sonic log, core velocities, and the caliper log from the lithodensity tool, it was clear that these low-velocity values were the result of poor tool contact because of unusually enlarged hole diameter. Very low velocity values were deleted in the intervals from 777.4 to $778 \mathrm{mbsf}$, from 798.6 to 800.4 mbsf, and from 867.9 to $868.5 \mathrm{mbsf}$, where the hole diameters were 16,17 , and 17 in, respectively. The deleted values were then replaced by interpolation across the gap.

Velocity measurements in the laboratory using DSV transducer pairs were performed on the discrete samples. For velocity measurements in very soft sediments, the DSV1 and/or DSV2 transducer pairs are inserted into the split core to measure vertical velocity and horizontal velocity, respectively, parallel to the face of the split core. The transducers are a fixed distance apart. Therefore, the results of these measurements are based on traveltime alone and are not operator dependent. No systematic inconsistencies in the data are apparent, and thus, the data are assumed to be of good quality. In the case of compacted sediments, measurements were made through the liner using the DSV3 transducer pair, which measures horizontal velocity perpendicular to the split core face. This procedure generates an increase in the measurement error, because the core is squeezed between the transducers during each measurement with a small, but generally different, amount of pressure. The same problem applies for measurements of consolidated sediment, where pieces of sediment are removed from the core liner and then pressed between the transducers. In the case of a weak signal or high noise, water is applied between the liner and transducers or onto the surface of the sediment pieces in order to improve sediment-transducer coupling.

\section{Porosity}

Downhole porosity was measured using the dual-porosity compensated neutron tool (Shipboard Scientific Party, 1996a). This tool contains an americium-beryllium source that emits neutrons that collide with the nuclei of formation materials. Greater energy loss of thermal neutrons occurs when the neutron strikes a nucleus of similar mass (i.e., a hydrogen nucleus). Therefore, a change in the number of neutrons detected at the receiver depends primarily on the amount of hydrogen in the formation, which is assumed to be related to the amount of liquid-filled pores. The tool also detects the hydrogen contained in minerals as bound water (hydroxyl ions). Thus for clay-rich sediments, the thermal neutron porosity tends to be overestimated. Additionally, elements with high thermal neutron cross section have a strong effect on neutron detection. However, this can be partially accounted for by comparing porosity determined from the thermal neutron detector with that determined from the epithermal detector, which is not affected by these elements (Hearst and Nelson, 1985). Another factor that diminishes the quality of the porosity measurements is hole diameter. Enlarged hole conditions will permit the neutrons to penetrate drilling fluid also (i.e., seawater), giving an erroneous estimate of porosity.

Laboratory porosity measurements from discrete core samples are affected by the same factors as index property density measurements. In contrast to log neutron porosity, the presence of clay in the sample does not affect the porosity because it has been shown that oven drying at a moderate temperature does not affect the hydroxyl ions bound in clays.

Editing of the downhole porosity log was based on a comparison with the caliper log. The intervals with erroneously high porosity peaks that correspond to hole irregularities were deleted. These intervals were at $475,527,538,776,805,843$, and $902 \mathrm{mbsf}$, with corresponding hole diameters of $4,4,16,16,15,14$, and 14 in. 


\section{RESULTS AND DISCUSSION Core and Log Data Comparison}

Core data are collected in the laboratory in quite different pressure and temperature conditions than that of the in situ logging data. Release of overburden stress may cause core expansion, microcracking, clay swelling, and associated changes in the elastic properties of sediments. When integrating core and log measurements, one must remember that these measurements were performed on different scales: for core, on a small, discrete sample, and for downhole, on the borehole wall (Goldberg, 1997). One must also consider different physical methods used to collect these data. Additionally, when core recovery is low there is a higher error in the estimation of the depths of core samples. These factors must be taken into account in data comparison, and they are, in addition to measurements errors, responsible for some scatter in the data sets.

The comparison of log density and core density results (Fig. 1A) shows that these two data sets are generally consistent with one another. The core data are more precisely measured than the log data, but lack the higher resolution provided by logging measurements. In the interval between 667 and $740 \mathrm{mbsf}$, the log data have slightly higher values than the core data. This discrepancy is most likely the result of a lithologic factor. This interval consists predominantly of clayey porcellanite, which contains less micrite cement than the sediments above and below. As a result, this material may expand slightly because of rebound effects, leading to small a though noticeable increase in volume (MacKillop et al., 1995; Moran, 1995). This increase in volume causes a decrease in the bulk density. Another interval where the data sets show a departure from each other is between 860 and 900 mbsf. This interval is within Unit III, which is a uniform black claystone. The uniformity of the lithology, therefore, does not explain the discrepancy. However, at this depth the caliper $\log$ shows an increase in hole diameter indicating washout (15 in). As a result, the logging density would be underestimated because the density tool then measures a combination of the formation density and seawater density.

As with the comparison of density measurements, core and log velocity data (Fig. 1A) show good agreement and follow the same trends, which adds confidence in the reliability of both data sets. In the upper part of Hole 959D to $740 \mathrm{mbsf}$, the core velocity is slightly less than the log velocity, especially at 667 and $740 \mathrm{mbsf}$, and, as in the case of density data, this is most likely a result of slight core expansion in the laboratory environment from the release of overburden pressure. However, below $740 \mathrm{mbsf}$ the sediments are more consolidated and thus less prone to expansion and disturbances, and so core and log velocity values show better agreement. Some features visible on the sonic log, such as velocity increases at 540 and $580 \mathrm{mbsf}$, were not detected by core measurements because of wide and possibly nonrepresentative sampling.

The most distinctive features to notice in values of thermal neutron porosity and index properties porosity plotted downhole (Fig. 1A) are their differences in the upper part of the logged interval of Hole 959D, from 400 to $740 \mathrm{mbsf}$. Although one is tempted to explain these differences by the expansion of sediments because of rebound, such a significant difference cannot be explained by a simple rebound correction because the density and velocity data do not show the same strong trends, but rather only slightly lower values from the laboratory measurement than from the in situ measurements. Assuming for a moment that this trend in porosity data from 400 to $740 \mathrm{mbsf}$ is real, one could try to explain the lack of similar trend in the lower part of the section from 740 to 1043 mbsf (Fig. 1A). Higher clay content could be responsible for the overestimation of log porosity in the lower section of the core (below $740 \mathrm{mbsf}$ ) because of detection of bound water by the thermal neutron tool. Correction for this overestimation would shift the log porosities to values below $740 \mathrm{mbsf}$. However, the sediments below 740 mbsf are not clays, but rather compacted black claystones (Shipboard Scientific Party, 1996c) which have very little bound water. Therefore, the neutron porosity is not necessarily overestimated in this section. This means that there must be some other factor explaining such a big discrepancy between core and $\log$ porosity data in the interval from 400 to $740 \mathrm{mbsf}$.

For the comparison with core porosity data, logging thermal neutron porosity was used. Some explanation for the discrepancy between core and log data may come from considering not only thermal neutron porosity, but epithermal neutron porosity as well (Fig. 2). Because the measurement of standard log porosity is based on the detection of thermal neutrons, the presence of thermal neutron absorbing elements (e.g., boron, chlorine, and rare earth) in the formation can decrease thermal porosity values. Epithermal neutron detection, however, is insensitive to these thermal neutron absorbing elements, but has a reduced detector counting rate that can decrease the statistical precision. To improve the statistics, the epithermal neutron source and detector must be very closely spaced, which leads to measurements that are overly sensitive to bad hole conditions (Davis et al., 1981). Core porosities and epithermal neutron porosities measured between 400 and 740 mbsf show good correlation and epithermal neutron porosities are consistently higher than thermal neutron porosities (Fig. 2). Below $740 \mathrm{mbsf}$, however, thermal neutron porosities correlate very well with core porosities, whereas epithermal porosities show poor correlation with core porosities caused by increased scatter, but do not seem to differ greatly from thermal porosity values. Thus, the mismatch between epithermal neutron and core porosity below $740 \mathrm{mbsf}$ is most likely the result of a degradation in the epithermal data resulting from very rough hole conditions, which can be seen in the caliper log (Fig. 2). In contrast, the difference between the thermal neutron and core porosities between 400 and $740 \mathrm{mbsf}$ is uniform and consistent with the effect of thermal neutron absorbing elements. The presence of chlorine in the drilling fluid, which is seawater, should not be the factor, because at Site 959 chloride concentrations are similar to seawater values and no anomalies were detected (Shipboard Scientific Party, 1996c). The sediments between 400 and 740 mbsf are comprised mainly of porcellanite with some minor amounts of micrite and clay (Shipboard Scientific Party, 1986c). Clay presents a difficulty because of variability with respect to concentrations of elements with large thermal neutron absorption cross section (Davis et al., 1981), so that even a very small amount of these elements has a strong effect on thermal neutrons. For example, the thermal capture cross section for boron is $4 \times 10^{5}$ times that of oxygen (Hearst and Nelson, 1985). Thus, small amounts of one nuclide can have more effect on thermal neutrons than large amounts of another. In fact illite may have an order of magnitude higher boron concentration than kaolinite or montmorillonite (Davis et al., 1981). To estimate the correction to porosity it is necessary to know the clay type and composition. Otherwise, epithermal porosity values should be used, as they are not as readily affected by these elements. The presence of elements with high thermal-neutron absorption cross section in the clays of Subunit IIC seems to be the most plausible explanation for the trends in porosity data at Site 959. A complete explanation would require careful geochemical analyses of the distribution of elements with large thermal-neutron absorption cross section, which is beyond the abilities of the existing geochemical logs.

\section{Rebound}

If laboratory measurements of core density and porosity are significantly different from the in situ values determined from logging, the laboratory values can generally be corrected if the amount of rebound is known. Such discrepancy between laboratory and in situ measurements is due to the increase in volume that occurs when the core is brought to substantially lower pressure at the earth's surface because of the removal of the overlying sediment column. Rebound 

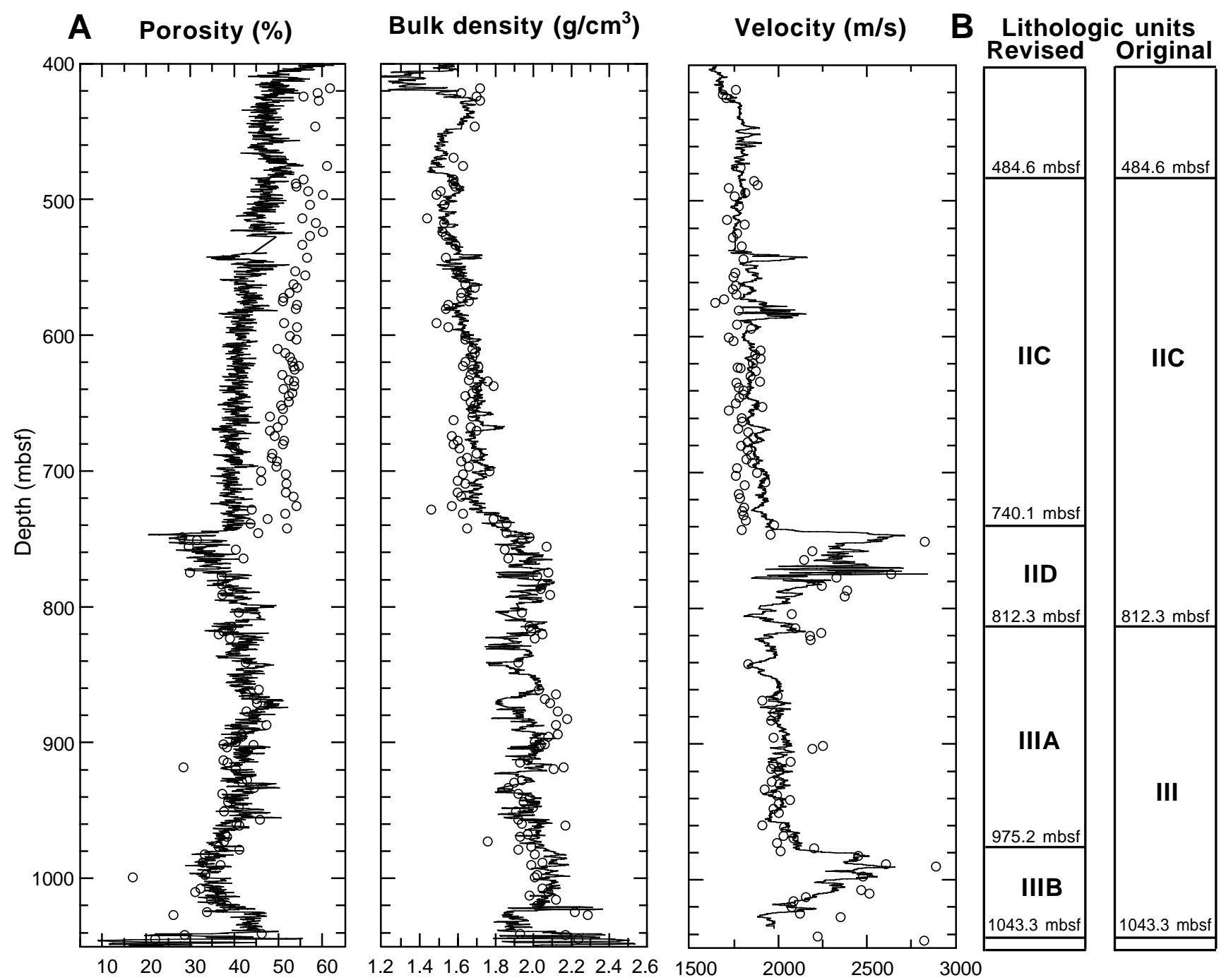

Figure 1. A. Comparison of logging data and core data at Hole 959D. Solid line = logging data, open circles = discrete core measurements. B. Revised lithologic units and original lithologic division.

effects are usually estimated from consolidation tests and have been found to be highly lithology dependent (Hamilton, 1976; MacKillop et al., 1995; Moran, 1995), and so should be performed for each representative sediment type. Jarrard et al. (1993) compared consolidation studies from different ODP legs and reached conflicting conclusions concerning rebound. Nevertheless, it is well accepted that the amount of rebound depends not only on overburden pressure from mbsf, but also on time, sediment type, and the degree of lithification, which reduces rebound (Fisher et al., 1992). Although no consolidation tests were performed on Leg 159 cores, a comparison of log and core data provides information regarding sediment expansion caused by pressure and temperature-induced core expansion. The integration of Hole 959D log and core density data that have been edited and corrected for core disturbances and measurement errors shows that most of the recovered core was sufficiently lithified, so that expansion was probably not significant enough to require rebound corrections of the discrete core bulk density and velocity data, with the exception of the interval from 660 to $740 \mathrm{mbsf}$.

\section{Petrophysical Data and Lithologic Units}

At Site 959 the sediment column was divided shipboard into five lithologic units based on visual core descriptions and smear slides
(Shipboard Scientific Party, 1996c). If these lithologic units were uniform, then the solid grain density (dry mass divided by dry volume of the sample) would be relatively constant and porosity-velocity or velocity-density crossplots (also called scatter-plots) would be nearly linear, or at least contain one trend. Thus, the examination of the aforementioned petrophysical relationships provides more intrinsic information about the character of the lithologic unit than that provided by qualitative sedimentological descriptions. The correct definition of lithologic units is essential for further geological studies of the Cote d'Ivoire-Ghana Transform Margin area.

There are two data sets suitable for the crossplots: physical properties laboratory measurements and in situ logging measurements. Comparative analysis shows that the main trends are similar in both data sets. However, because logging data have higher resolution and better coverage, they were chosen for the crossplot analyses. The crossplots were prepared for lithologic Subunit IIC (porcellanite with clay and micrite) and Unit III (black claystone, claystone with nannofossils) recovered in Hole 959D (Fig. 3), but not for Subunits IIA, IIB, IVA, and IVB and Unit V, because these latter units had an insufficient number of measurements because of their smaller thicknesses (Shipboard Scientific Party, 1996c). There is some scatter in the crossplots because there was measurement error from minor hole roughness that was not extreme enough to warrant removal of data 

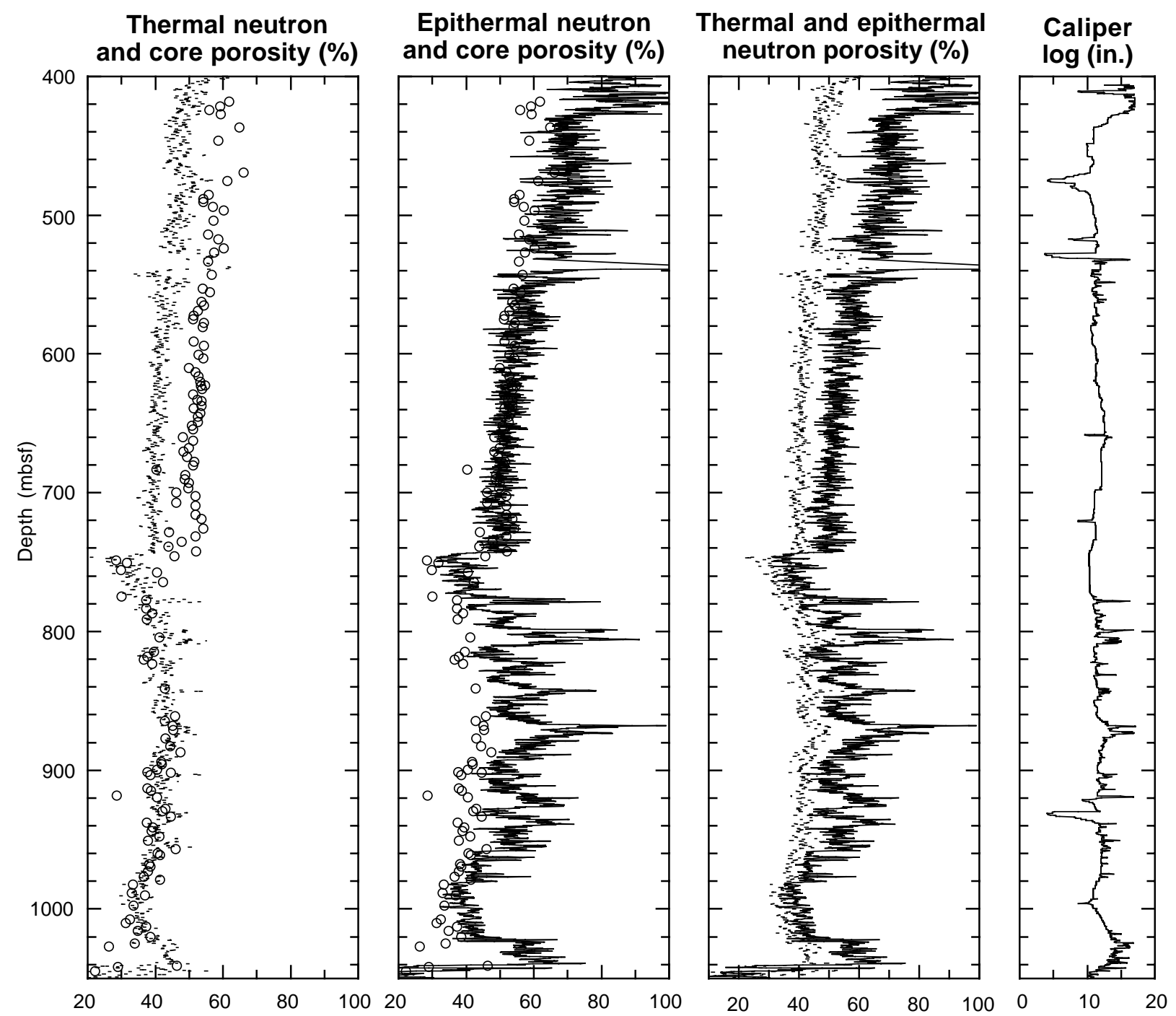

Figure 2. Comparison of thermal and epithermal neutron porosity data with core measurements from Hole 959D, alongside the caliper log. Dashed line $=$ thermal neutron porosity, solid line $=$ epithermal neutron porosity, open circles $=$ discrete core porosity data.

points during the editing process. Also, lithologic units do not generally comprise one pure sediment type, but usually are of one predominant lithotype, with smaller amounts of other sediment types either interbedded or sparsely distributed. This nonuniformity influences the distribution of solid grain density throughout the lithologic units and is also seen as a nonlinearity in the crossplots. Nevertheless, there are two trends in each of the crossplots that are too distinctive to be explained by measurement error (Fig. 3). This would mean that the lithologic units are not uniform and, therefore, a more precise division would better describe the recovered sedimentary column.

As a result of analyzing of crossplot clusters, an improved division of the sedimentary column is proposed with two new units and a redefinition of the old units. In addition, crossplots are presented for the units of the improved division (Fig. 1B) based on an examination of density, velocity, porosity, and geochemical logs for the logged and cored interval of Hole 959D. The lower boundary of Subunit IIC has been shifted from 812.3 to $740.1 \mathrm{mbsf}$, because of noticeable increase in velocity and density, and the sharp decrease in porosity at 740.1 mbsf. Below this depth, Subunit IID has been defined as the 72-m-thick interval from 740.1 to 812.3 mbsf, which is differentiated from the sediments above and below by significantly higher velocity, slightly higher density, and lower porosity (Fig. 1A). The crossplot of porosity with velocity for the Subunit IID shows a linear trend, whereas the velocity vs. density relationship is characterized by a highly scattered distribution of points (Fig. 4). The physical explanation of these relationships could be intensive cementation of the sediments with micrite. Micritization sharply reduces porosity, thus increasing velocity without a strong increase in density. Other evidence supporting the addition of Subunit IID is the geochemical log, which shows a higher $\mathrm{CaCO}_{3}$ content for this interval (micrite) than for adjacent intervals (Fig. 5), and by the strong seismic reflection at this depth interval, which is associated with the cemented micritic porcellanite of high acoustic impedance (Edwards, Chap. 22, this volume).

The top of Unit III remains at 812.3 mbsf. However, the bottom of Unit III is now moved from 1043 to 975.2 mbsf (Fig. 1). The redefined Unit III is now named Subunit IIIA. Subunit IIIA consists mainly of black claystone, with uniform physical properties throughout the interval, and some scatter in the crossplots probably resulting from the presence of minor amounts of pyrite (Shipboard Scientific Party, 1996a). Subunit IIIB begins at 975.2 mbsf, a depth at which the velocity increases sharply from 2000 to almost $2500 \mathrm{~m} / \mathrm{s}$, and ends at 1043 mbsf. Crossplots for Subunit IIIB clearly show a single linear trend. This unit contains claystones that are more compacted than those above, and contains dolomite and barite. There is also sediment 

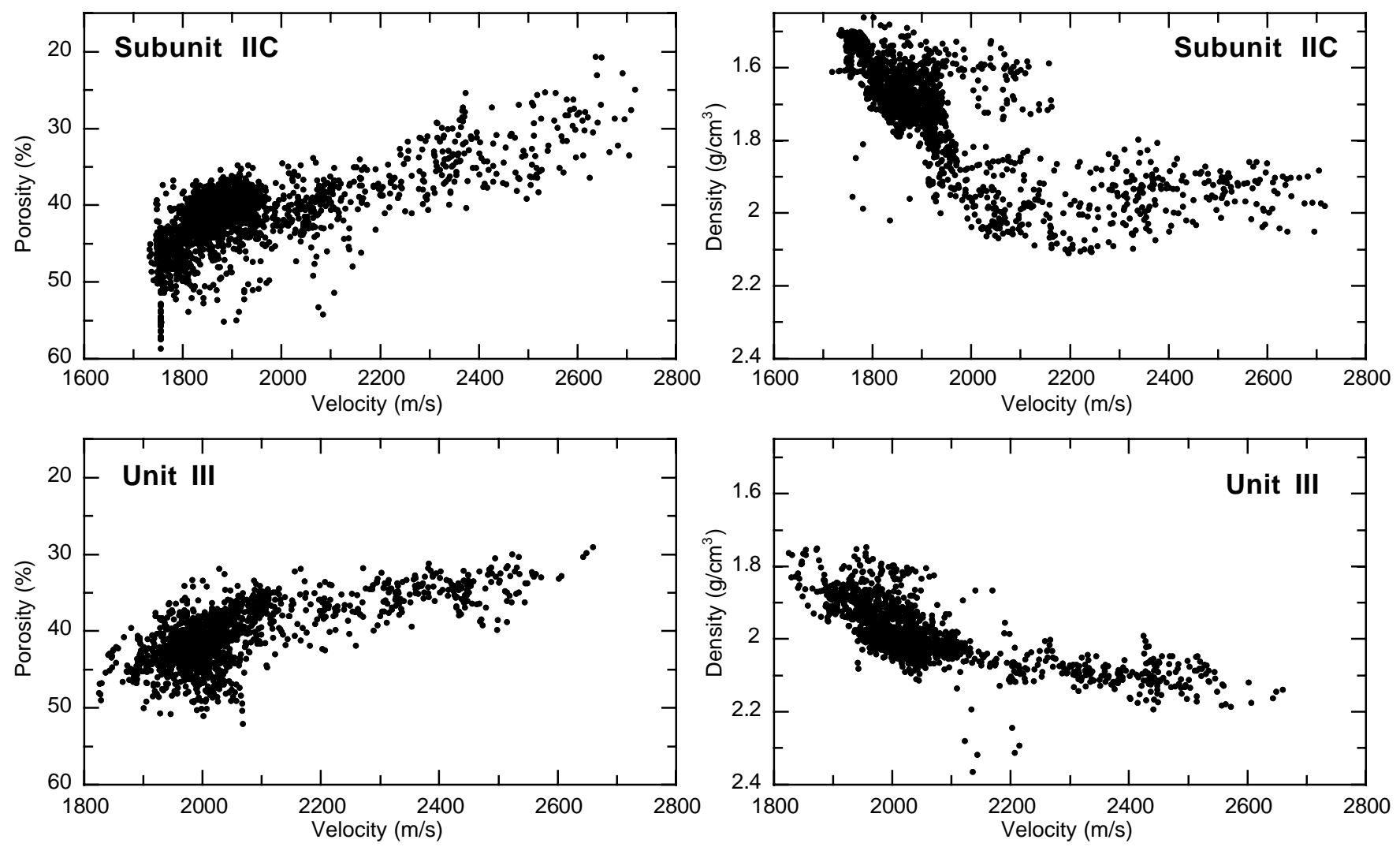

Figure 3. Porosity-velocity and density-velocity crossplots for Subunit IIC and Unit III of the original lithologic division at Hole 959D.

color change at the transition from Subunit IIIA to Subunit IIIB, from black to dark and medium gray. In addition to the differences in the physical properties data, there is also a difference in the clay mineralogy (Pletsch et al., 1996). The predominant clay types in Subunit IIIB are illite-bearing assemblages, whereas in the overlying black claystones of Unit IIIA, assemblages are almost exclusively composed of smectite with some minor kaolinite. The two new subunits, Subunits IID and IIIB, seem to be affected by chemical diagenesis and cementation after burial. Their chemical micro-environment must have been different from those of the adjacent sediments, and so they should be interpreted as distinct subunits.

\section{CONCLUSIONS}

The core and log data sets collected during ODP Leg 159 are consistent with each other and, therefore, can be used with a high degree of confidence in future geological studies. Detailed comparison of thermal and epithermal neutron porosity data provides complimentary techniques helpful in proper interpretation of collected measurements. Simple qualitative analyses of the clusters on scatter-plots of geophysical data provide a tool to aid in a more appropriate definition of lithologic units. The proposed revisions of the lithologic units in the interval between 484.6 and 1043.3 mbsf better reflect sediment type variations with depth. The core and log data sets collected during ODP Leg 159 provide a more precise assessment of lithologic divisions. The improved divisions suggested in this paper enable improved geological and tectonic interpretations, because they more precisely distinguish between different intervals based on sediment type. The combination of sedimentological techniques and physical properties data can provide an improved method for describing a sedimentary column, and with higher resolution data available, still fur- ther subdivisions could be made. However, with regard to the objectives of Leg 159 to ascertain constraints for larger scale plate tectonic models of margin development, our additional subdivisions suffice, whereas the shipboard division may not account for some significant features, which could influence future geological interpretations.

\section{ACKNOWLEDGMENTS}

Thanks to S. Morita and T. Akamaluk, who shared the responsibility of collecting the shipboard physical properties data. We would like to thank Keir Becker, Gerardo Iturrino, and an anonymous reviewer for critically reviewing the manuscript, and Don McNeill for helpful comments. Special thanks to Kim Rosen for patience and help with the manuscript. This research was supported in part by funds from JOI/USSAC.

\section{REFERENCES}

Basile, C., Mascle, J., Popoff, M., Bouillin, J.P., and Mascle, G., 1993. The Côte d'Ivoire-Ghana transform margin: a marginal ridge structure deduced from seismic data. Tectonophysics, 222:1-19.

Davis, R.R., Hall, J.E., Boutemy, Y.L., and Flaum, C., 1981. A dual porosity CNL logging system. In Foster, N., and Beaumont A. (Eds.), Formation Evaluation I: Log Evaluation. Treatise of Petrol. Geol. Reprints Ser., 16:389-396

Edwards, R.A., Whitmarsh, R.B., and Scruton, R.A., 1997. The crustal structure across the transform continental margin off Ghana, eastern Equatorial Atlantic. J. Geophys. Res., 102:747.

Fisher, A.T., Abrams, L., and Busch, W.H., 1992. Comparison of laboratory and logging data from Leg 129 and the inversion of logs to determine lithology. In Larson, R.L., Lancelot, Y., et al., Proc. ODP, Sci. Results, 129: College Station, TX (Ocean Drilling Program), 507-527. 
Goldberg, D., 1997. GRL special section on core-log-seismic data integration. Geophys. Res. Lett., 24:315.

Hamilton, E.L., 1976. Variations of density and porosity with depth in deepsea sediments. J. Sediment. Petrol., 46:280-300.

Hearst, J.R., and Nelson, P.H., 1985. Well Logging for Physical Properties: New York (McGraw-Hill).

Jarrard, R.D., Jackson, P.D., Kasschau, M., and Ladd, J.W., 1993. Velocity and density of carbonate-rich sediments from northeastern Australian margin: integration of core and log data. In McKenzie, J.A., Davies, P.J., Palmer-Julson, A., et al., Proc. ODP, Sci. Results, 133: College Station, TX (Ocean Drilling Program), 633-647.

Lovell, M.A., and Morin, R.H., 1989. Physical-properties characterization of sediments in the area around DSDP/ODP Hole 504B. In Becker, K., Sakai, H., et al., Proc. ODP, Sci. Results, 111: College Station, TX (Ocean Drilling Program), 233-244.

MacKillop, A.K., Moran, K., Jarrett, K., Farrell, J., and Murray, D., 1995. Consolidation properties of equatorial Pacific Ocean sediment and their relationship to stress history and offsets in the Leg 138 composite depth sections. In Pisias, N.G., Mayer, L.A., Janecek, T.R., Palmer-Julson, A., and van Andel, T.H. (Eds.), Proc. ODP, Sci. Results, 138: College Station, TX (Ocean Drilling Program), 357-369.

Moran, K., 1995. Sediment elastic properties applied to the Ocean Drilling Program composite depth scale: examples from Leg 154, Ceara Rise. 5th Int. Conf. Paleoceanogr., Halifax. (Abstract)

O'Brien, D.K., and Manghnani, M.H., 1992. Physical properties of Site 762: a comparison of shipboard and shore-based laboratory results. In von
Rad, U., Haq, B.U., et al., Proc. ODP, Sci. Results, 122: College Station, TX (Ocean Drilling Program), 349-362.

Pletsch, T., Erbacher, J., Kuhnt, W., and ODP Leg 159 Shipboard Scientific Party, 1996. Clay minerals of Cretaceous and Paleogene deposits from the eastern Equatorial Atlantic: preliminary results from ODP Leg 159 (Côte d'Ivoire-Ghana Transform Margin). European ODP Meeting. (abstract)

Schlumberger, 1989. Log Interpretation Principles/Applications: Houston, TX (Schlumberger Educ. Services).

Shipboard Scientific Party, 1996a. Explanatory notes. In Mascle, J., Lohmann, G.P., Clift, P.D., et al., Proc. ODP, Init. Repts., 159: College Station, TX (Ocean Drilling Program), 17-46.

1996b. Introduction. In Comas, M.C., Zahn, R., Klaus, A., et al. Proc. ODP, Init. Repts., 161: College Station, TX (Ocean Drilling Program), 5-19.

1996c. Site 959. In Mascle, J., Lohmann, G.P., Clift, P.D., et al., Proc. ODP, Init. Repts., 159: College Station, TX (Ocean Drilling Program), 65-150.

Date of initial receipt: 16 September 1996

Date of acceptance: 20 April 1997

Ms 159SR-044 

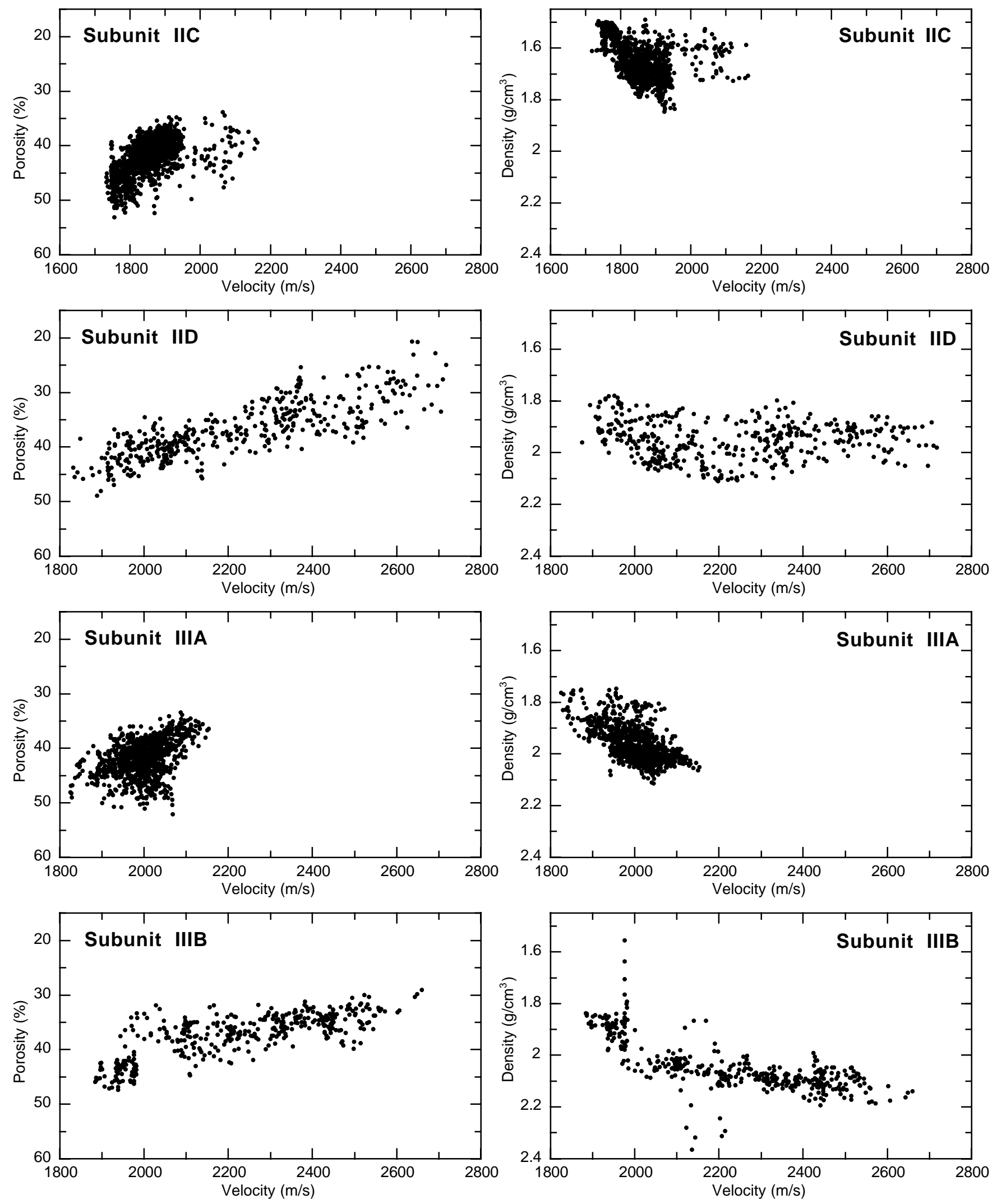

Figure 4. Porosity-velocity and density-velocity crossplots for Subunits IIC, IID, IIIA, and IIIB of the revised lithologic division at Hole 959D. 


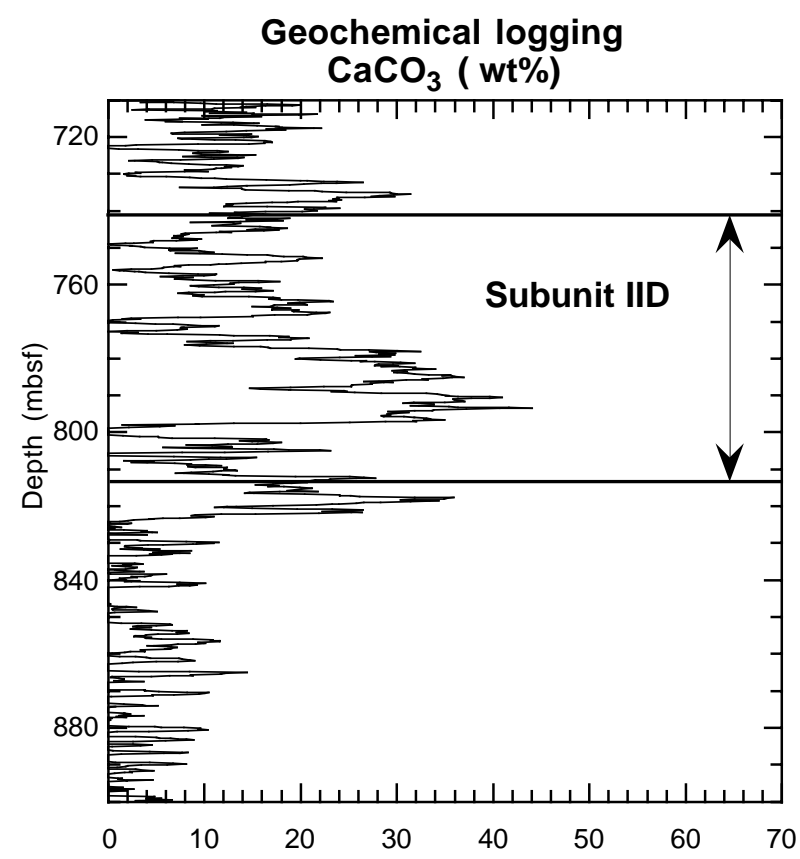

Figure 5. $\mathrm{CaCO}_{3}$ weight percent content estimated from geochemical logging data at Hole 959D, Subunit IID. 